\title{
Oxytocin Reduces Background Anxiety in a Fear-Potentiated Startle Paradigm
}

\author{
Galen Missig', Luke W Ayers', Jay Schulkin² and Jeffrey B Rosen*,' \\ 'Department of Psychology, Behavioral Neuroscience Program, University of Delaware, Newark, DE, USA; '2Department of Neuroscience, \\ Georgetown University, Washington, DC, USA; Behavioral Endocrinology Section, National Institute of Mental Health, Bethesda, MD, USA; \\ Research Department, American College of Obstetricians and Gynecologists, Washington, DC, USA
}

\begin{abstract}
Oxytocin reportedly decreases anxious feelings in humans and may therefore have therapeutic value for anxiety disorders, such as post-traumatic stress disorder (PTSD). As PTSD patients have exaggerated startle responses, a fear-potentiated startle paradigm in rats may have face validity as an animal model to examine the efficacy of oxytocin in treating these symptoms. Oxytocin (0, 0.0 I, 0.I, or $1.0 \mu \mathrm{g}$, subcutaneously) was given either $30 \mathrm{~min}$ before fear conditioning, immediately after fear conditioning, or 30 min before fear-potentiated startle testing to assess its effects on acquisition, consolidation, and expression of conditioned fear, respectively. Startle both in the presence and absence of the fear-conditioned light was significantly diminished by oxytocin when administered at acquisition, consolidation, or expression. There was no specific effect of oxytocin on light fear-potentiated startle. In an additional experiment, oxytocin had no effects on acoustic startle without previous fear conditioning. Further, in a context-conditioned test, previous light-shock fear conditioning did not increase acoustic startle during testing when the fear-conditioned light was not presented. The data suggest that oxytocin did not diminish cue-specific conditioned nor contextually conditioned fear, but reduced background anxiety. This suggests that oxytocin has unique effects of decreasing background anxiety without affecting learning and memory of a specific traumatic event. Oxytocin may have antianxiety properties that are particularly germane to the hypervigilance and exaggerated startle typically seen in PTSD patients.

Neuropsychopharmacology (2010) 35, 2607-26I6; doi:I0.1038/npp.20 I0.155; published online 15 September 2010
\end{abstract}

Keywords: oxytocin; anxiety; fear; startle; PTSD

\section{INTRODUCTION}

Oxytocin has recently received considerable attention for its role in social behavior, and as a possible target for a number of psychiatric disorders, particularly, anxiety, post-partum depression, and autism (Carter, 2007; Heinrichs et al, 2009; Macdonald and Macdonald, 2010; Marazziti and Catena Dell'osso, 2008; Neumann, 2008). Oxytocin is a nonapeptide released in blood from the hypothalamo-neurohypophysial system and other peripheral organs, and in the brain within the hypothalamus, amygdala, bed nucleus of the stria terminals, brainstem, and other regions from neurons originating in the hypothalamic paraventricular and supraoptic nuclei (Gimpl and Fahrenholz, 2001; Kiss and Mikkelsen, 2005).

\footnotetext{
*Correspondence: Professor JB Rosen, Department of Psychology, Behavioral Neuroscience Program, University of Delaware, 108 Wolf Hall, Newark, DE 19716, USA, Tel: + I 302 831-4209, Fax: + I 302 831-3645, E-mail: jrosen@udel.edu

Received 10 May 2010; revised 8 August 2010; accepted 9 August 2010
}

Exogenous oxytocin has anxiolytic effects. Peripheral and central injections of oxytocin in rats and mice reduce anxiety in a number of tests when stress is high or induced (Rotzinger et al, 2010). Subcutaneous injections of oxytocin and oxytocin fragments in rats reduce retention of passive avoidance (Boccia and Baratti, 2000; de Oliveira et al, 2007; de Wied et al, 1987). Rats given low subcutaneous doses $(1-4 \mu \mathrm{g} / \mathrm{kg})$ of oxytocin spent more time in the center of an open field, similar to the behavior of rats given the anxiolytic benzodiazepine drug midazolam (Uvnäs-Moberg et al, 1994). A high-stress strain of Sprague-Dawley rats that typically perform poorly on conditioned avoidance showed significantly improved learning when given systemic oxytocin pretreatment (Uvnäs-Moberg et al, 2000).

In humans, exogenous intranasally administered oxytocin has anxiolytic effects in males (Domes et al, 2007; Heinrichs et al, 2003; Kirsch et al, 2005), diminishes aversive conditioning (Petrovic et al, 2008), and promotes emotional facial recognition (Di Simplicio et al, 2009; Fischer-Shofty et al, 2010) and memory (Savaskan et al, 2008). Oxytocin may have potential therapeutic use in social anxiety disorder (Guastella et al, 2009), autism (Andari et al, 
2010), and possibly post-traumatic stress disorder (PTSD) (Pitman et al, 1993).

Acoustic startle as a measure of sensorimotor responsivity and anxiety (Braff et al, 2001; Davis et al, 2010; Swerdlow et al, 2008; Vaidyanathan et al, 2009) is also affected by oxytocin, but results are variable. High doses of oxytocin had no effect on startle (Feifel and Reza, 1999), but lower doses increased startle when tested in the dark phase of the day (King et al, 1985). Oxytocin null mice displayed low (Winslow et al, 2000) or normal (Caldwell et al, 2009) startle amplitudes. Oxytocin receptor knockout mice had normal acoustic startle (Lee et al, 2008). Oxytocin also did not affect pre-pulse inhibition of startle (PPI) by itself (Feifel and Reza, 1999), but disruption of PPI by phencyclidine was enhanced in oxytocin null mice (Caldwell et al, 2009), and oxytocin and a receptor agonist, WAY267464, reversed the disruption in PPI induced by amphetamine and MK-801 in rats (Feifel and Reza, 1999; Ring et al, 2010). Highly emotional rats that have low plasma levels of oxytocin have increased startle (UvnäsMoberg et al, 1999). Similarly, Nair et al (2005) demonstrated that oxytocin receptor binding in the lateral septum was negatively correlated with the amplitude of startle potentiated by social isolation. Finally, humans homozygous for the $G$ allele (GG) of a single-nucleotide polymorphism within intron 3 of the OXTR gene had lower levels of stress reactivity in anticipation of a startle stimulus than individuals with one or two copies of the A allele (AA and AG) polymorphism (Rodrigues et al, 2009). Together, these studies suggest that endogenous oxytocin and exogenously administered oxytocin modulate anxious states of rodents and humans.

Oxytocin has not been tested in fear-potentiated startle, which is often used as a measure of conditioned anticipatory anxiety and may model the hypervigilance and exaggerated startle responses typically seen in PTSD patients (Grillon and Morgan, 1999; Grillon et al, 2009b; Jovanovic et al, 2010, 2009; Morgan et al, 1995). One advantage of the fear-potentiated startle paradigm is that drug effects on fear or anxiety can usually be dissociated from motoric effects of drugs (Davis et al, 1993; Fendt et al, 2010; Joordens et al, 1998; Walker and Davis, 2002a). In the present experiments, oxytocin was administered systemically at various phases of learning, memory, and expression of fear to investigate its effects on acquisition, consolidation, and expression of conditioned fear. Our findings indicate a unique anxiolytic profile for oxytocin on startle and background anxiety, a state not directly related to cue-specific or contextually conditioned fear, but sustained beyond the immediate threat (Walker and Davis, 2002b).

\section{MATERIALS AND METHODS}

\section{Animals}

A total of 240 male Sprague-Dawley rats weighing between 225 and $250 \mathrm{~g}$ were obtained from Charles River Laboratories (Wilmington, MA). The rats were pair-housed in shoebox cages in a climate-controlled facility with a $0700-$ 1900 hours light/dark cycle. Rats had free access to food and water. At 1 week after arrival, experiments were started and were performed between 0800 and 1600 hours.
All procedures were in accordance with the US National Institutes of Health Guide for the Care and Use of Experimental Animals and approved by the University of Delaware IACUC.

\section{Apparatus}

Eight identical SR Lab ventilated startle chambers with clear Plexiglas cylinders (San Diego Instruments, San Diego, CA) were used for training and testing. On one wall of each chamber, three LED lights in parallel produced 2600 lux and served as the conditioned stimulus (CS). A floor insert made of ten $4-\mathrm{mm}$ diameter stainless steel tubes placed $4 \mathrm{~mm}$ apart inside the Plexiglas cylinder to deliver footshocks was used. Background white noise of $65 \mathrm{~dB}$ was continually played throughout all experimental sessions.

\section{Experiment Design}

Each experiment followed the basic paradigm: 3 days of startle acclimation/matching, 1 day of classical fear conditioning, and after a 96-h gap, a fear-potentiated startle test session. Deviations from this pattern are noted below in the Experiment sections.

\section{Startle Acclimation/Matching}

For the first 3 days of the experiment, rats were habituated to the chamber and presented with startle stimuli. For each daily session, there was a 5-min acclimation period followed by 30 trials of startle stimuli. The series of trials consisted of white noise bursts of 10 trials each of 95,105 , or $115 \mathrm{~dB}$ noise bursts presented in a predetermined pseudorandom pattern with a $15 \mathrm{~s}$ intertrial interval. On the third day of acclimation, the startle amplitudes were averaged for each rat and the mean startle score was used to sort the rats into matched groups with similar levels of startle. The rats were then rehoused and paired with a member of the same group.

\section{Fear Conditioning}

On the fourth day, the rats were classically fear conditioned to the light. Following a 5-min acclimation period, five pairings of $3 \mathrm{~s}$ of the light CS co-terminating with a $500 \mathrm{~ms}$, $0.6 \mathrm{~mA}$ foot shock occurred. The intertrial intervals ranged from 60 to $180 \mathrm{~s}$.

\section{Fear-Potentiated Startle Testing}

After a 96-h rest, the rats were tested for fear-potentiated startle. The testing consisted of $5 \mathrm{~min}$ of acclimation followed by 70 startle trials with $15 \mathrm{~s}$ intervals. The first 10 trials that consisted of $95 \mathrm{~dB}$ noise bursts were not used in any analyses. The next 60 trials consisted of 95, 105, or $115 \mathrm{~dB}$ noise bursts, with half presented either in the dark or co-terminating with the $3 \mathrm{~s}$ light CS. Thus, for each noise burst intensity, there were 10 trials in the dark and 10 trials co-terminating with the light. The trials were presented in a predetermined pseudorandom pattern. 


\section{Oxytocin Administration}

Each group of rats was administered either $0,0.01,0.1$, or $1.0 \mu \mathrm{g} / \mathrm{ml} / \mathrm{kg}$ of oxytocin dissolved in saline (Bachem Americas, Torrance, CA, catalog number H-2510). The choice of doses was based on studies of de Wied et al (1987) and Boccia et al (1998). The choice of injections $30 \mathrm{~min}$ before the session was based on Ring et al (2006). A frozen stock solution of $10 \mu \mathrm{g} / \mathrm{ml}$ oxytocin was diluted before each experiment and maintained on ice. Injections were given subcutaneously at the scruff of the neck.

\section{Experiment 1: Oxytocin During Acquisition}

Injections were given $30 \mathrm{~min}$ before conditioning to examine the effect on acquisition of learned fear. Doses of $0.0,0.01,0.1$, and $1.0 \mu \mathrm{g} / \mathrm{kg}$ oxytocin were tested with 12 rats in each condition for a total of 48 rats.

\section{Experiment 2: Oxytocin During Consolidation}

Injections were given $20 \mathrm{~min}$ after conditioning to determine the effect on fear consolidation. Again vehicle and the same three doses were tested with 12 rats in each condition.

\section{Experiment 3: Oxytocin During Expression}

Injections were given $30 \mathrm{~min}$ before fear-potentiated startle testing on the eighth day ( $96 \mathrm{~h}$ after acquisition) to test for the effect on expression of fear-potentiated startle. The same doses of oxytocin were tested with 12 rats per dose.

\section{Experiment 4: Oxytocin on the Acoustic Startle Response Without Fear Conditioning}

This experiment tested whether oxytocin suppressed the ability to startle. Acclimation and matching were performed similarly as previously described. On the fourth day, rats were not put into the testing chambers, nor were they conditioned (no lights, no shocks). On the eighth day, oxytocin was administered $30 \mathrm{~min}$ before acoustic startle testing. Instead of using a combination of Light + Noise and Noise-only trials, the 30 trials presented during acclimation was used. The same doses of oxytocin were tested with 12 rats per dose.

\section{Experiment 5: Oxytocin on Context Fear-Potentiated Startle}

In addition to fear conditioning to the explicit cue, conditioning also occurs to the context during cue-specific fear conditioning. Testing for contextually conditioned fear is typically conducted by returning the subject to the context without presentation of the explicit fear CS (Jacobs et al, 2010). To examine whether oxytocin influenced contextually conditioned fear-potentiated startle or not, the same 3 days of acclimation, group matching for startle response, and light-shock fear conditioning on the fourth day were performed as described above. After $96 \mathrm{~h}$, rats were given saline or oxytocin, and $30 \mathrm{~min}$ later, instead of testing cue-specific light CS fear-potentiated startle, contextual fear was examined by presenting only Noise trials.
Thus, instead of receiving a combination of 60 Light + Noise and Noise trials, rats received 60 Noise trials in the same pseudorandom order as before. The same doses of oxytocin were tested with 12 rats per dose.

\section{Data Analysis}

For experiments 1 through 3, three startle scores were used for the statistical analyses: Pre-Fear startle, Noise, and Light + Noise. Startle amplitudes of each rat induced by the 95, 105 , and $115 \mathrm{~dB}$ noise bursts (30 trials) from the last (third) acclimation session were averaged to obtain a single score of Pre-Fear startle. The same was done for the 30 Noise and 30 Noise + Light trials in the fear-potentiated startle test for Noise and Light + Noise scores, respectively. These scores were then used for statistical analyses.

The effect of oxytocin in the fear-potentiated startle test was analyzed by a mixed model ANOVA with a betweensubject measure of dose (4 doses) and within-subject measure of fear-potentiated startle (Light + Noise vs Noise). Post hoc analysis of a main effect of dose on startle was performed with a Dunnett's test to compare the various doses of oxytocin to the vehicle (saline). Cue-specific conditioned fear was analyzed to two ways - using absolute fear-potentiated startle or proportional fear-potentiated startle scores. An absolute fear-potentiated startle score was computed by subtracting the average Noise startle amplitude from its average Light + Noise startle amplitude of each rat. A proportional fear-potentiated startle score for each rat was computed dividing the absolute fear-potentiated startle score by the average Noise startle amplitude. Analysis of proportional fear-potentiated startle was done to standardize the groups because fear-potentiated may be distorted by the baseline effects on oxytocin (Walker and Davis, 2002a). Dunnett's tests were used for these analyses.

A measure of change in startle amplitude after fear conditioning, which we call background anxiety, was also computed. Pre-Fear startle was compared with the Noise trials from the fear-potentiated startle test. Similar to the analysis of fear-potentiated startle described above, a mixed model ANOVA with a between-subject measure of dose and withinsubject measure of background anxiety (Pre-Fear vs Noise) was performed. Post hoc analysis of a main effect of dose was performed with a Dunnett's test to compare the various doses of oxytocin to the vehicle (saline). A significant interaction effect was further analyzed with a Dunnett's test after the startle data was converted into background anxiety score (Noise minus Pre-Fear startle scores).

Experiments 4 and 5 did not test for Light + Noise startle. The Pre-Fear and Noise startle scores were statistically analyzed in a similar manner as the background anxiety measure of experiments 1-3. An $\alpha$ value of $p<0.05$ was considered a significant difference for all the analyses described above, but trends $(p<0.1)$ are also presented in graphs.

\section{RESULTS}

The two important comparisons in this study are shown in Figure 1. Background anxiety is the comparison between Noise startle amplitude and Pre-Fear startle amplitude, and is the facilitating effect of cue-specific fear conditioning on 


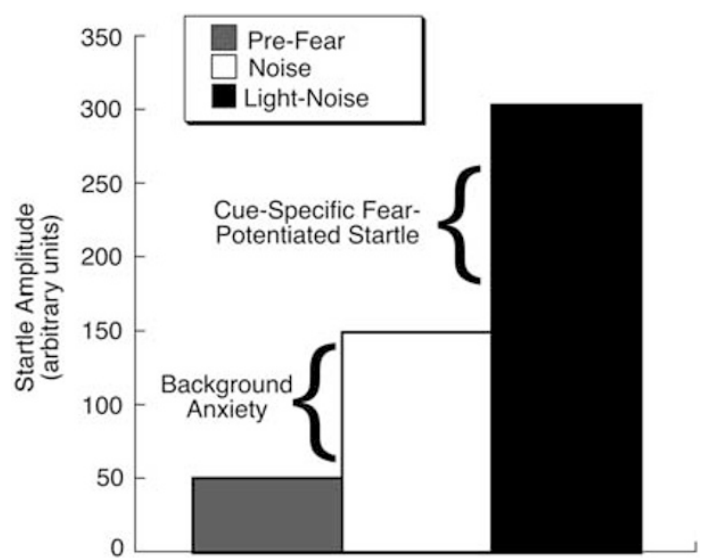

Figure I Sample startle responses. Startle from three different trial types were used to analyze the effects of oxytocin. Background anxiety is the increase in startle amplitude in the Noise trials during the fear-potentiated startle test compared with startle amplitude during the last acclimation session (Pre-Fear startle). Cue-specific fear-potentiated startle is the increase is startle amplitude in the Light + Noise trials compared with startle amplitude in the Noise trials during the fear-potentiated startle test.

Noise trials in the fear-potentiated startle test. Cue-specific fear-potentiated startle is the increase in Light + Noise startle amplitude compared with Noise startle amplitude due to the Light + footshock fear conditioning.

In general, regardless of when oxytocin was administered (ie, acquisition, consolidation or expression), it had similar effects on background anxiety and cue-specific fearpotentiated startle, but the effects were statistically most robust when oxytocin was administered $30 \mathrm{~min}$ before acquisition session or the fear-potentiated startle test. Oxytocin dose dependently diminished background anxiety and acoustic startle both in the presence and absence of light, but had no specific effect on cue-specific fearpotentiated startle.

\section{Experiment 1: Oxytocin Effects on Acquisition}

There was a significant main effect of cue-specific fearpotentiated startle (Light + Noise trials different from Noise trials, $\left.\mathrm{F}_{1,44}=106.1, p<0.0001\right)$ and a trend for a main effect of oxytocin dose on startle amplitude $\left(\mathrm{F}_{3,44}=2.33\right.$, $p<0.088)$. A Dunnett's test revealed a significant reduction in acoustic startle by $0.1 \mu \mathrm{g}$ oxytocin compared with saline $(p<0.034$, Figure 2a). There was no interaction effect indicating that oxytocin did not affect cue-specific fearpotentiated startle using absolute fear-potentiated startle scores. This was supported using proportional fearpotentiated startle scores (Figure $2 \mathrm{~b}$ ). Background anxiety was only marginally reduced by oxytocin. A mixed model ANOVA revealed a main effect of an increase in startle in Noise trials compared with Pre-Fear trials $\left(\mathrm{F}_{1,44}=27.0\right.$, $\mathrm{p}<0.0001)$. A Dunnett's test showed that there was a trend for the $0.1 \mu \mathrm{g}$ dose of oxytocin to diminish background anxiety compared with saline $(p=0.064$, Figure $2 c)$.

\section{Experiment 2: Oxytocin Effects on Consolidation}

Similar to oxytocin given before acquisition, there was a significant within-measure main effect of fear-potentiated startle $\left(\mathrm{F}_{1,44}=147.8, p<0.0001\right.$; Figure $\left.3 \mathrm{a}\right)$. There was a trend for a between-measure main effect of oxytocin on startle amplitude $\left(\mathrm{F}_{3,44}=2.81, p<0.092\right)$ and a Dunnett's test suggests this is because of reduced startle with $0.1 \mu \mathrm{g}$ oxytocin compared with saline $(p<0.046$, Figure $3 a)$. There was a significant interaction effect $\left(\mathrm{F}_{3,44}=3.06, p<0.038\right)$ suggesting an effect of oxytocin on cue-specific fearpotentiated startle using absolute fear-potentiated startle scores. However, a Dunnett's test using proportional fearpotentiated startle scores was not significant indicating oxytocin did not affect cue-specific fear-potentiated startle when the scores were standardized (Figure $3 b$ ). Testing for significance of background anxiety, there was a significant overall increase in Noise startle $\left(\mathrm{F}_{1,44}=173.2, p<0.0001\right)$, but no main effect of oxytocin dose on startle amplitude, nor an interaction. A Dunnett's test suggests there was a trend for a reduction in background anxiety with $0.1 \mu \mathrm{g}$ oxytocin $(p<0.08)$.

\section{Experiment 3: Oxytocin Effects on Expression}

Scores were not obtained from one rat because of equipment malfunction. The effects of oxytocin given $30 \mathrm{~min}$ before the fear-potentiated startle test were similar to the effects on acquisition and consolidation. There was a significant main effect of fear-potentiated startle $\left(\mathrm{F}_{1,43}=\right.$ $129.18, p<0.0001)$ and a significant main effect of oxytocin dose on startle amplitude $\left(\mathrm{F}_{3,43}=3.07, p=0.038\right)$. Shown in Figure $4 \mathrm{a}$, Dunnett's test revealed that the $0.01 \mu \mathrm{g}$ dose of oxytocin significantly diminished startle $(p=0.022)$ and the $0.1 \mu \mathrm{g}$ dose just missed significantly reducing startle $(p=0.054)$. There was no effect of oxytocin on fearpotentiated startle using either absolute or proportional scores of fear-potentiated startle (Figure 4b). Analyzing background anxiety, there was an overall increase in startle to Noise compared with Pre-Fear startle $\left(\mathrm{F}_{1,43}=23.93\right.$, $p<0.0001)$. Oxytocin reduced background anxiety (Figure 4c). There was no main effect of oxytocin dose on startle amplitude, but there was significant interaction $\left(\mathrm{F}_{3,43}=3.14, p=0.035\right)$. A Dunnett's test on the interaction effect revealed that $0.1 \mu \mathrm{g}$ oxytocin significantly reduced background anxiety compared with saline $(p=0.022)$, and the other two oxytocin doses displayed a trend for reducing background anxiety $(0.001 \mu \mathrm{g}, p=0.094 ; 1.0 \mu \mathrm{g}, p=0.054)$.

\section{Experiment 4: Oxytocin does not Reduce the Ability to Startle}

The previous experiments demonstrated that oxytocin reduces acoustic startle both in the absence and presence of the fear conditioned stimulus. While we are calling this a reduction in background anxiety, an alternative explanation is that oxytocin simply interferes with the ability to startle or respond to the acoustic stimulus. To test whether oxytocin is merely reducing the startle response, rats were not fear conditioned, but tested for startle amplitude with or without oxytocin. Within-subject comparisons were made between startle before receiving oxytocin and $30 \mathrm{~min}$ after oxytocin administration (Figure 5a). There were no effects of any dose of oxytocin on startle amplitude. Thus, oxytocin may not merely reduce the ability to startle, but seems to reduce startle subsequent to fear conditioning. 

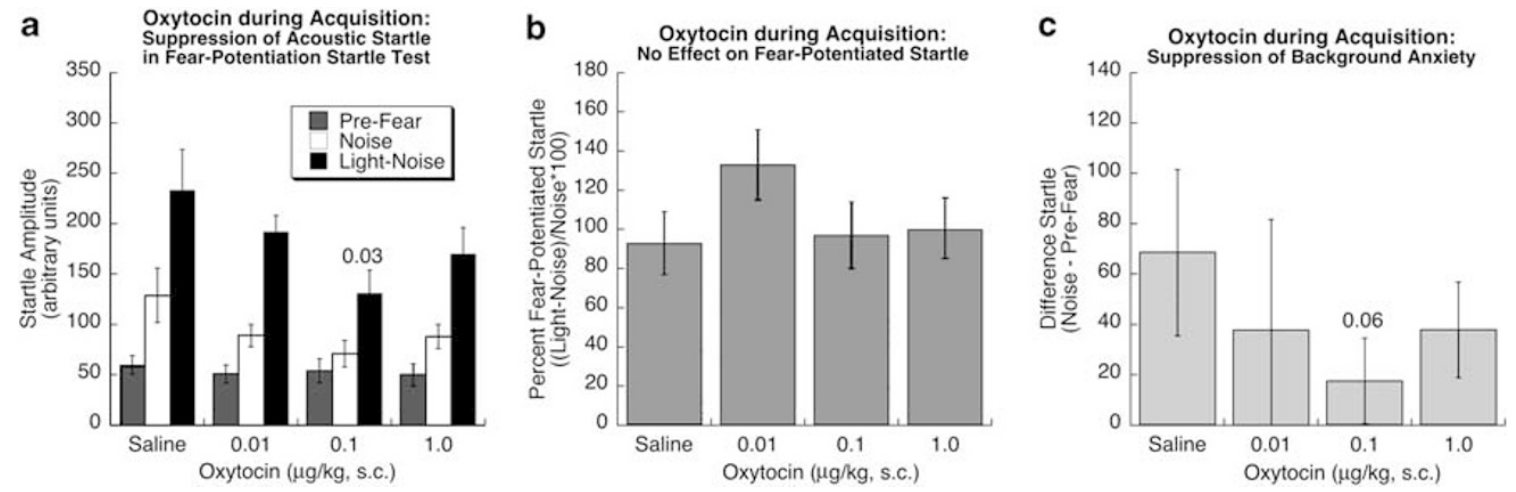

Figure 2 Effect of oxytocin administered before the acquisition phase. (a) Mean startle amplitudes of the three different trial types. The 0.03 above the Noise and Light + Noise startle scores is the p-value of the difference in startle between saline and 0.I $\mu$ g oxtyocin. No other comparisons approached statistical significance. (b) Proportional fear-potentiated startle scores. There were no statistical differences between any dose of oxytocin and saline. (c) Background anxiety scores. The 0.06 is the p-value of the difference in background anxiety startle scores between saline and $0.1 \mu \mathrm{g}$ oxytocin. No other comparisons approached statistical significance.
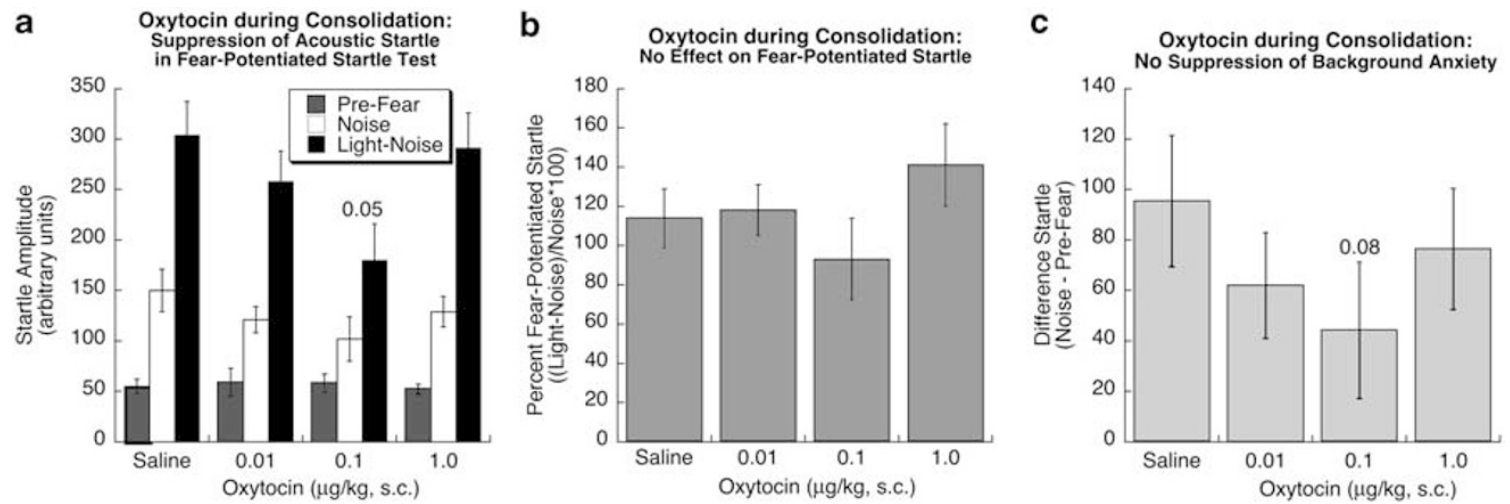

Figure 3 Effect of oxytocin administered in the consolidation phase. (a) Mean startle amplitudes of the three different trial types. The 0.05 above the Noise and Light + Noise startle scores is the $p$-value of the difference in startle between saline and $0.1 \mu g$ oxytocin. No other comparisons approached statistical significance. (b) Proportional fear-potentiated startle scores. There were no statistical differences between any dose of oxytocin and saline. (c) Background anxiety scores. There were no statistical differences between any dose of oxytocin and saline, but the $0.1 \mu \mathrm{g}$ dose approached significance $(p<0.08)$.
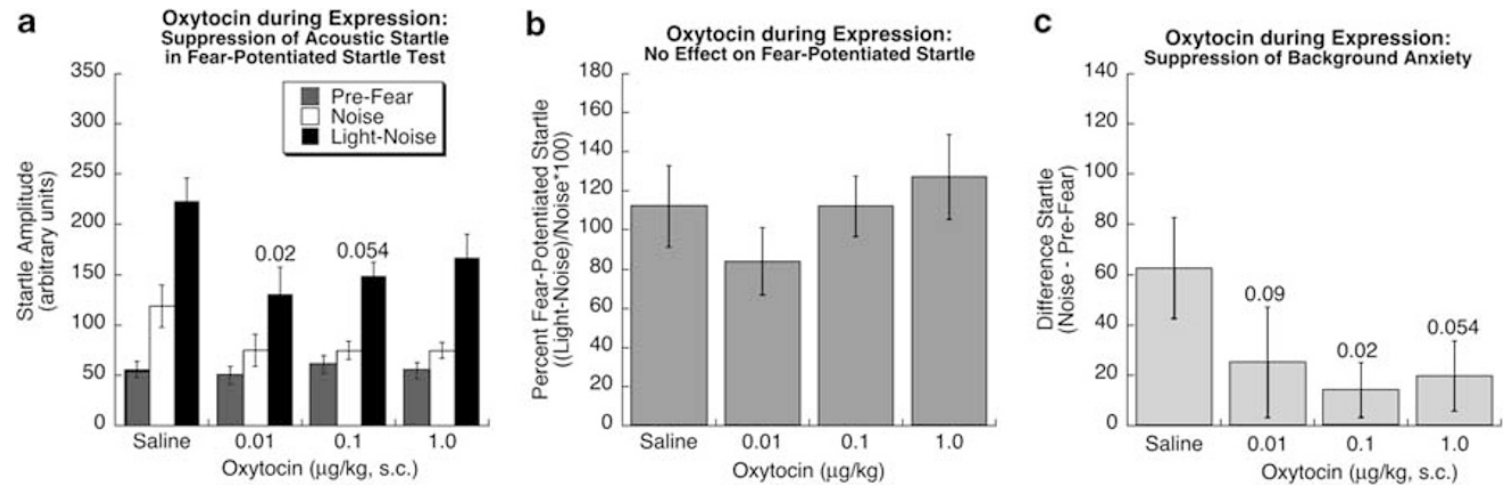

Figure 4 Effect of oxytocin administered before the fear-potentiated startle expression test. (a) Mean startle amplitudes of the three different trial types. The 0.02, and 0.054 above the Noise and Light + Noise startle scores are the respective $p$-values of the differences in startle between saline and the $0.0 \mathrm{I}$ and $0.1 \mu \mathrm{g}$ doses of oxytocin. (b) Proportional fear-potentiated startle scores. There were no statistical differences between any dose of oxytocin and saline. (c) Background anxiety scores. The 0.09, 0.02, and 0.054 are the p-values of the differences in background anxiety startle scores between saline and the $0.0 \mathrm{I}$, 0.1 , and $1.0 \mu \mathrm{g}$ doses of oxytocin, respectively.

It is possible, however, that the lack of an effect of oxytocin on startle amplitude was because startle levels were very low in this experiment, and oxytocin may be more effective in reducing high levels of startle like those generated in experiments 1 through 3 following fear conditioning. We therefore reanalyzed the data of experiment 4 
a
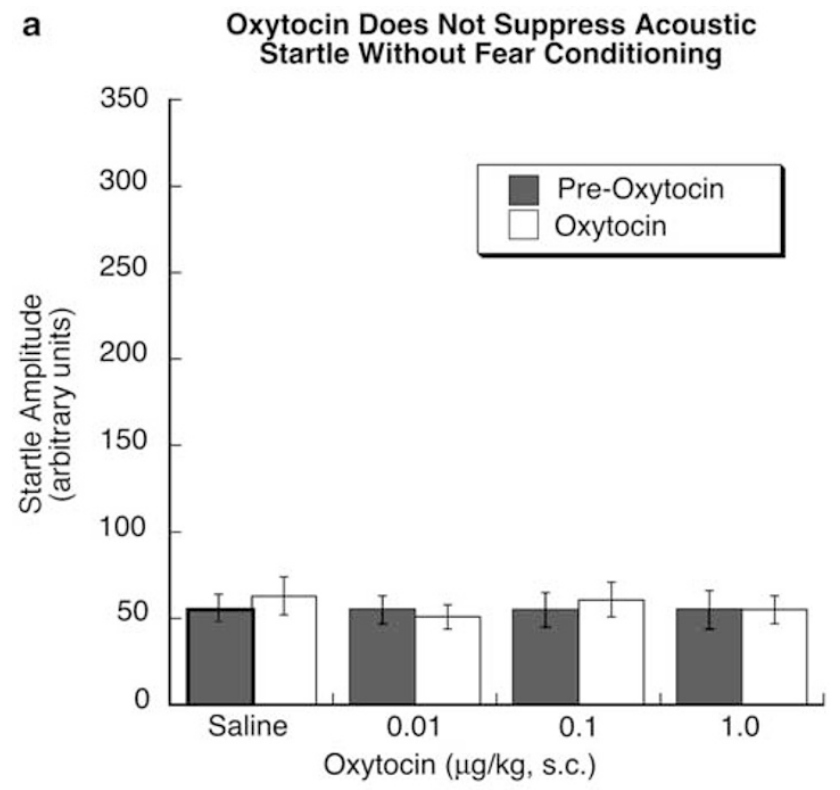

b

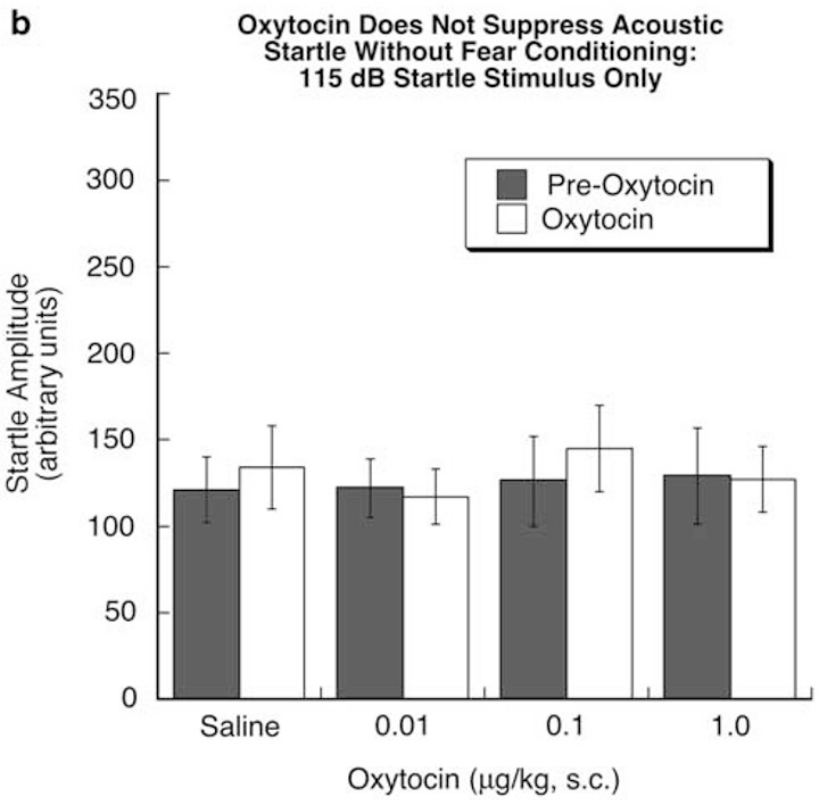

Figure 5 No effect of oxytocin on acoustic startle in rats that were not fear conditioned. (a) Startle amplitudes averaged from the 95, 105, and II $5 \mathrm{~dB}$ startle stimuli. (b) Startle amplitudes from the $115 \mathrm{~dB}$ startle stimulus only.

using startle amplitudes induced by the three startle stimulus intensities, 95, 105, and $115 \mathrm{~dB}$ noise bursts, individually. There were no effects of oxytocin on startle elicited at any of these intensities. The mean pre-oxytocin and oxytocin startle amplitudes of the saline group induced by the $115 \mathrm{~dB}$ noise burst were 134 and 145 , respectively (Figure $5 \mathrm{~b}$ ). These amplitudes are similar to the mean of the combined 95, 105, and $115 \mathrm{~dB}$ induced startle amplitudes of the Noise trials in the saline groups after fear conditioning in experiments 1 through 3 , in which the startle amplitude means ranged from 119 to 150 startle units. Therefore, because similar levels of startle amplitude were reduced by oxytocin following fear conditioning, but not affected by oxytocin without previous fear conditioning, it is likely that

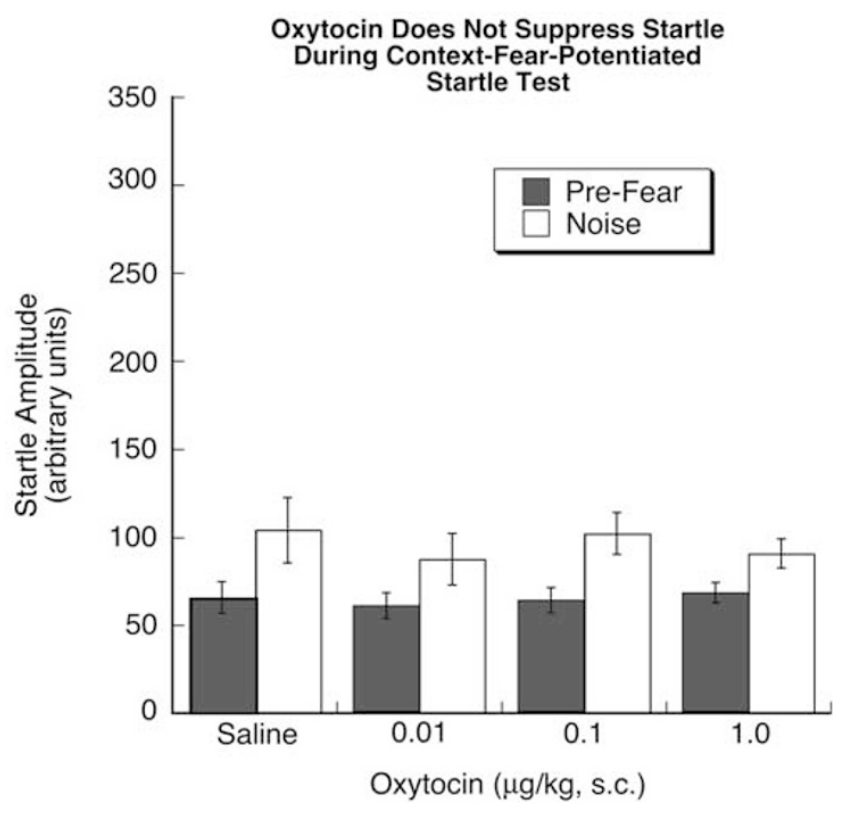

Figure 6 Test of contextually conditioned fear. No effect of oxytocin on acoustic startle in fear-conditioned rats not presented with the light CS during startle testing. There was a significant increase in startle in the Noise test compared with the Pre-Fear test in all the groups, indicating contextually conditioned fear. There were no differences in startle between the saline and oxytocin groups.

oxytocin reduces background anxiety and not the ability to startle.

\section{Experiment 5: Oxytocin does not Reduce Contextually Conditioned Fear}

Whereas we suggest that oxytocin is reducing background anxiety, it is possible that oxytocin interferes with conditioned contextual fear instead. To test this explanation, rats were tested for Pre-Fear acoustic startle amplitude, fear conditioned to the light, but then tested for startle without presenting the fear-conditioned light. Thus, if oxytocin decreased startle in the test without ever presenting the fear CS, it would indicate that oxytocin reduced contextually conditioned fear. There was a significant main effect of an increase in startle after fear conditioning $\left(\mathrm{F}_{1,44}=47.62\right.$, $p<0.0001)$, but no significant main effect of oxytocin at any dose, nor an interaction effect (Figure 6). The results indicate that contextually conditioned fear was produced, but oxytocin did not reduce this conditioned fear as measured by startle amplitude, and suggest that the effects of oxytocin on startle in experiments 1 through 3 were due to its effects on some kind of background anxiety that is different from contextually conditioned fear.

\section{DISCUSSION}

The results of the present experiments indicate that oxytocin has unique effects on startle as measured in a fear-potentiated startle paradigm. Oxytocin did not have specific effects on cue-specific conditioned fear-potentiated startle, which is different from the cue-specific reduction of 
fear-potentiated in rodents and monkeys by antianxiety drugs such as diazepam and buspirone (Davis, 1979; Joordens et al, 1998; Kehne et al, 1988; Risbrough et al, 2003; Winslow et al, 2007). Oxytocin, however, had a novel suppressant effect on startle, both in the presence and absence of the fear CS, but only if the fear CS was presented during the test. Furthermore, the increase in startle to Noise alone subsequent to fear conditioning (ie, background anxiety) was diminished by oxytocin. This unusual effect suggests that exogenous oxytocin acts as an anxiolytic agent, but does not diminish learned fear to a cue-specific or context CS. As discussed later, oxytocin may have particular therapeutic relevance for PTSD patients.

Subcutaneous oxytocin was shown to reduce acoustic startle given either during acquisition, consolidation, or expression of conditioned fear. Cue-specific fear-potentiated startle was not affected by oxytocin given at acquisition or expression (and with the proportional, but not absolute, fear-potentiated startle measure for consolidation), indicating that even though oxytocin diminished startle, there was no effect of oxytocin on cue-specific fear in the learning and expression phases. It is possible that oxytocin given during acquisition blunted nociception (Lundeberg et al, 1994) during fear conditioning, but there was no evidence of reduced cue-specific fear-potentiated startle in the acquisition experiment. Oxytocin also did not reduce the expression of acoustic startle in nonconditioned rats, nor contextually conditioned fear. These experiments indicate that oxytocin did not interfere with the ability to startle, nor the ability to learn cue-specific and contextually conditioned fear.

It is possible that oxytocin given before the fearpotentiated startle test reduced cue-specific fear. In this explanation, fear activated by the fear-conditioned light lingers through the 15-s intertrial intervals to enhance startle in the Noise-alone trials. Oxytocin might reduce cuespecific fear and consequently suppress the lingering fear throughout the intertrial interval and the Noise-alone trials. Although this possibility was not tested directly, de Jongh et al (2003) demonstrated that startle was not potentiated when the Noise was delivered 1-5 s after the offset of the light CS. This suggests that in our experiments the increase of startle in Noise-alone trials and its reduction by oxytocin were not due to cue-specific fear persisting into the Noise trials. Nonetheless, this explanation would need to be tested empirically before it is firmly rejected, possibly by testing whether there are lingering effects of the cue-specific fear $\mathrm{CS}$ in a novel context.

We hypothesize that oxytocin diminishes what we call background anxiety. This is an anxiety state not directly related to the cue-specific fear CS nor contextually conditioned fear cues, but is activated by the fear CS. This background state is evident during the testing of fear-potentiated startle by an increase in acoustic startle during Noise trials compared with acoustic startle in the Pre-Fear startle tests. Startle both in the absence and presence of the light fear CS was suppressed by oxytocin, but only if the light fear CS was presented during the fearpotentiated startle test session. Oxytocin given before acquisition or during consolidation could also diminish background anxiety without affecting learning and memory. The reduced background anxiety would then carryover to the test of expression to diminish startle when exogenous oxytocin was not present. Thus, oxytocin might be uniquely effective in reducing some type of background anxiety during a threatening situation that is not cue-specifically nor context-specifically conditioned.

A background anxiety-like phenomenon in a fearpotentiated startle paradigm has been observed before. Concomitant with intra-amygdala NMDA receptor blockade of cue-specific fear-potentiated startle, Walker and Davis (2002b) found a persistent increase in 'baseline' startle in both Noise and Light + Noise trials coinciding with the first light fear CS presentation. Background anxiety appears to be activated by cue-specific fear, but might be independent of it, likely because the two phenomena are subserved by different neural circuits (Walker and Davis, 2002b).

We conducted a test for contextually conditioned fear typically used in fear-conditioning experiments (Jacobs et al, 2010). Oxytocin had no effect on the contextual fearconditioned increase in startle, which is different from the reduction of contextually conditioned fear in $\mathrm{CRH}$ receptor knockout mice using a shock-potentiated startle paradigm (Risbrough et al, 2009). Shock-potentiated startle, in which no explicit cues are paired with shock (Davis, 1989), enhances startle when wild-type animals are returned to the shock chamber (McNish et al, 1997; Richardson, 2000; Risbrough et al, 2009). Antagonism or knockout of CRH receptors reduces contextually conditioned shock-potentiated startle, but cue-specific fear-potentiated startle is not affected (Risbrough et al, 2009). Our conditioning protocol of contextual fear was different from the shock-potentiated startle paradigm, in that shock was paired with an explicit cue, relegating context conditioning to the background. In shock-potentiated startle, there is no cue-specific stimulus, and thus the context acts as a foreground stimulus similar to an explicit cue (Rescorla and Wagner, 1972). Whether oxytocin is also ineffective in a shock-potentiated startle paradigm with context as a foreground cue is a question for further research.

In our paradigm, oxytocin was effective at very low doses in the submicrogram range. Most studies of peripheral injections of oxytocin on anxiety tests (eg, elevated plus maze, light-dark box, open field, and acoustic startle) test doses in the milligram range (Feifel and Reza, 1999; King et al, 1985; Rotzinger et al, 2010). The submicrogram range effective in our studies is similar to those used in many intracerebroventricular and intracerebral infusion studies (Rotzinger et al, 2010). However, our doses are similar to those used in studies of peripherally administered oxytocin on inhibitory avoidance in rats (de Oliveira et al, 2007; de Wied et al, 1987; Kovacs et al, 1978) and post-training administration in mice (Boccia et al, 1998). Thus, startle appears to be as sensitive behavioral measure as passive avoidance for peripherally administered oxytocin, but does not answer the question of whether the site(s) of action are peripheral or central. Peripheral and central oxytocin systems are regulated differently, release very different amounts of oxytocin, and metabolize oxytocin at different rates, suggesting that the two systems are largely independent (Veening et al, 2010). We have preliminary data that oxytocin infused into the lateral ventricle in the same range of doses we administered subcutaneously might not reduce fear-potentiated startle or background anxiety (Ayers et al, 
2010). In the periphery, oxytocin might possibly be acting by modulating glucocorticoid release at the adrenal glands (de Oliveira et al, 2007) or at the heart and vasculature to influence heart rate and blood pressure, as oxytocin receptors are located in these organs (Kiss and Mikkelsen, 2005). Clearly, much more research is needed before the sites of action and mechanisms of oxytocin on background anxiety are known.

The unique effects of oxytocin on startle in the fearpotentiated startle paradigm may have particular relevance for PTSD. Potentiation of startle in PTSD patients may be particularly sensitive to 'context fear' or 'contextualization' (Grillon, 2002; Liberzon and Sripada, 2008; RougemontBücking et al, 2010), but not cued fear. The nature of this context fear in human studies is not clear-it may be a result of contextual fear conditioning, verbal instructions of the experiment, or increased fear/anxiety induced by the aversiveness of the experiments (Böcker et al, 2001, 2004; Grillon, 2002; Rougemont-Bücking et al, 2010). Context fear might be the same as what we call background anxiety, that is, 'fear-potentiated startle is riding on an already elevated baseline' (Grillon, 2002). In our case, the background anxiety is not contextually conditioned fear, and is likely analogous to the hypervigilance and sensitized emotional anticipation (Rosen and Schulkin, 1998) hypothesized to increase startle in the face of perceived threats accompanying patients with PTSD and panic disorder (Grillon et al, 1994; Grillon and Morgan, 1999; Grillon et al, 2009b; Morgan et al, 1995). In this regard, combat veterans with PTSD also display disruptions in PPI (Grillon et al, 1998, 1996), a nonlearned measure of sensorimotor gating (Braff et al, 2001), and oxytocin and an oxytocin receptor agonist reverse drug-induced disruption in PPI in rodents (Feifel and Reza, 1999; Ring et al, 2010). Therefore, oxytocin might specifically alleviate one or more physiopathologies of PTSD.

The effect of oxytocin on background anxiety in our fearpotentiated startle studies in rats is also reminiscent of the findings from some studies with anxiolytic and antidepressant drugs on context fear in humans, in which aprazolam, diazepam, oxazepam, and a 2-week treatment of citalopram reduce increased baseline startle, but not cue-specific fearpotentiated startle (Baas et al, 2002; Grillon et al, 2006, 2009a). This does not appear to be due to sedative effects of the drugs, but to a reduction in context fear (Grillon et al, 2006). Oxytocin similarly reduces increased background anxiety without diminishing cue-specific fear-potentiated startle, and does not appear to produce sedation, or at least, diminish the ability to startle. Testing of oxytocin in fearpotentiated startle in humans awaits future research.

\section{ACKNOWLEDGEMENTS}

This work was supported by Grant W81XWH-08-1-0182 from the Congressionally Directed Medical Research Programs, US Army Medical Research and Materiel Command.

\section{DISCLOSURE}

The authors declare no conflict of interest.

\section{REFERENCES}

Andari E, Duhamel J-R, Zalla T, Herbrecht E, Leboyer M, Sirigu A (2010). Promoting social behavior with oxytocin in highfunctioning autism spectrum disorders. Proc Natl Acad Sci USA 107: 4389-4394.

Ayers LW, Missig G, Schulkin J, Rosen JB (2010). Systemic, but not intracerebroventricular, administration of oxytocin results in an attenuation of background anxiety in a fear-potentiated startle paradigm. Program No. 705.24. Society for Neuroscience: Neuroscience Meeting Planner, San Diego, CA. Online.

Baas JM, Grillon C, Bocker KB, Brack III AA, Morgan CA, Kenemans JL et al (2002). Benzodiazepines have no effect on fearpotentiated startle in humans. Psychopharmacology 161: 233-247.

Boccia MM, Baratti CM (2000). Involvement of central cholinergic mechanisms in the effects of oxytocin and an oxytocin receptor antagonist on retention performance in mice. Neurobiol Learn Mem 74: 217-228.

Boccia MM, Kopf SR, Baratti CM (1998). Effects of a single administration of oxytocin or vasopressin and their interactions with two selective receptor antagonists on memory storage in mice. Neurobiol Learn Mem 69: 136-146.

Böcker KB, Baas JM, Kenemans JL, Verbaten MN (2001). Stimuluspreceding negativity induced by fear: a manifestation of affective anticipation. Int J Psychophysiol 43: 77-90.

Böcker KBE, Baas JMP, Kenemans JL, Verbaten MN (2004). Differences in startle modulation during instructed threat and selective attention. Biological Psychol 67: 343-358.

Braff DL, Geyer MA, Swerdlow NR (2001). Human studies of prepulse inhibition of startle: normal subjects, patient groups, and pharmacological studies. Psychopharmacology (Berl) 156: 234-258.

Caldwell HK, Stephens SL, Young WS (2009). Oxytocin as a natural antipsychotic: a study using oxytocin knockout mice. $\mathrm{Mol}$ Psychiatry 14: 190-196.

Carter CS (2007). Sex differences in oxytocin and vasopressin: implications for autism spectrum disorders? Behav Brain Res 176: $170-186$.

Davis M (1979). Diazepam and flurazepam: effects on conditioned fear as measured with the potentiated startle paradigm. Psychopharmacology (Berl) 62: 1-7.

Davis M (1989). Sensitization of the acoustic startle reflex by footshock. Behav Neurosci 103: 495-503.

Davis M, Falls WA, Campeau S, Kim M (1993). Fear-potentiated startle: a neural and pharmacological analysis. Behav Brain Res 58: 175-198.

Davis M, Walker DL, Miles L, Grillon C (2010). Phasic vs sustained fear in rats and humans: role of the extended amygdala in fear vs anxiety. Neuropsychopharmacology 35: 105-135.

de Jongh R, Groenink L, van der Gugten J, Olivier B (2003). Lightenhanced and fear-potentiated startle: temporal characteristics and effects of alpha-helical corticotropin-releasing hormone. Biol Psychiatry 54: 1041-1048.

de Oliveira LF, Camboim C, Diehl F, Consiglio AR, Quillfeldt JA (2007). Glucocorticoid-mediated effects of systemic oxytocin upon memory retrieval. Neurobiol Learn Mem 87: 67-71.

de Wied D, Gaffori O, Burbach JP, Kovacs GL, van Ree JM (1987). Structure activity relationship studies with C-terminal fragments of vasopressin and oxytocin on avoidance behaviors of rats. J Pharmacol Exp Ther 241: 268-274.

Di Simplicio M, Massey-Chase R, Cowen PJ, Harmer CJ (2009). Oxytocin enhances processing of positive vs negative emotional information in healthy male volunteers. J Psychopharmacol (Oxf) 23: $241-248$.

Domes G, Heinrichs M, Gläscher J, Büchel C, Braus DF, Herpertz SC (2007). Oxytocin attenuates amygdala responses to emotional faces regardless of valence. Biol Psychiatry 62: 1187-1190. 
Feifel D, Reza T (1999). Oxytocin modulates psychotomimeticinduced deficits in sensorimotor gating. Psychopharmacology (Berl) 141: 93-98.

Fendt M, Imobersteg S, Bürki H, McAllister KH, Sailer AW (2010). Intra-amygdala injections of neuropeptide $S$ block fearpotentiated startle. Neurosci Lett 474: 154-157.

Fischer-Shofty M, Shamay-Tsoory SG, Harari H, Levkovitz Y (2010). The effect of intranasal administration of oxytocin on fear recognition. Neuropsychologia 48: 179-184.

Gimpl G, Fahrenholz F (2001). The oxytocin receptor system: structure, function, and regulation. Physiol Rev 81: 629-683.

Grillon C (2002). Startle reactivity and anxiety disorders: aversive conditioning, context, and neurobiology. Biol Psychiatry 52: 958-975.

Grillon C, Ameli R, Goddard A, Woods SW, Davis M (1994). Baseline and fear-potentiated startle in panic disorder patients. Biol Psychiatry 35: 431-439.

Grillon C, Baas JMP, Pine DS, Lissek S, Lawley M, Ellis V et al (2006). The benzodiazepine alprazolam dissociates contextual fear from cued fear in humans as assessed by fear-potentiated startle. Biol Psychiatry 60: 760-766.

Grillon C, Chavis C, Covington MF, Pine DS (2009a). Two-week treatment with the selective serotonin reuptake inhibitor citalopram reduces contextual anxiety but not cued fear in healthy volunteers: a fear-potentiated startle study. Neuropsychopharmacology 34: 964-971.

Grillon C, Morgan CA (1999). Fear-potentiated startle conditioning to explicit and contextual cues in Gulf War veterans with posttraumatic stress disorder. J Abnorm Psychol 108: 134-142.

Grillon C, Morgan III CA, Davis M, Southwick SM (1998). Effects of experimental context and explicit threat cues on acoustic startle in Vietnam veterans with posttraumatic stress disorder. Biol Psychiatry 44: 1027-1036.

Grillon C, Morgan CA, Southwick SM, Davis M, Charney DS (1996). Baseline startle amplitude and prepulse inhibition in Vietnam veterans with posttraumatic stress disorder. Psychiatry Res 64: 169-178.

Grillon C, Pine DS, Lissek S, Rabin S, Bonne O, Vythilingam M (2009b). Increased anxiety during anticipation of unpredictable aversive stimuli in posttraumatic stress disorder but not in generalized anxiety disorder. Biol Psychiatry 66: 47-53.

Guastella AJ, Howard AL, Dadds MR, Mitchell P, Carson DS (2009). A randomized controlled trial of intranasal oxytocin as an adjunct to exposure therapy for social anxiety disorder. Psychoneuroendocrinology 34: 917-923.

Heinrichs M, Baumgartner T, Kirschbaum C, Ehlert U (2003). Social support and oxytocin interact to suppress cortisol and subjective responses to psychosocial stress. Biol Psychiatry 54: 1389-1398.

Heinrichs M, von Dawans B, Domes G (2009). Oxytocin, vasopressin, and human social behavior. Front Neuroendocrinol 30: $548-557$.

Jacobs NS, Cushman JD, Fanselow MS (2010). The accurate measurement of fear memory in Pavlovian conditioning: resolving the baseline issue. J Neurosci Methods 190: 235-239.

Joordens RJ, Hijzen TH, Olivier B (1998). The anxiolytic effect on the fear-potentiated startle is not due to a non-specific disruption. Life Sci 63: 2227-2232.

Jovanovic T, Norrholm SD, Blanding NQ, Phifer JE, Weiss T, Davis $\mathrm{M}$ et al (2010). Fear potentiation is associated with hypothalamic-pituitary-adrenal axis function in PTSD. Psychoneuroendocrinology 35: 846-857.

Jovanovic T, Norrholm SD, Fennell JE, Keyes M, Fiallos AM, Myers $\mathrm{KM}$ et al (2009). Posttraumatic stress disorder may be associated with impaired fear inhibition: relation to symptom severity. Psychiatry Res 167: 151-160.

Kehne JH, Cassella JV, Davis M (1988). Anxyolytic effects of buspirone and gepirone in the fear-potentiated startle paradigm. Psychopharmacology 94: 8-13.
King MG, Brown R, Kusnecov A (1985). An increase in startle response in rats administered oxytocin. Peptides 6: 567-568.

Kirsch P, Esslinger C, Chen Q, Mier D, Lis S, Siddhanti S et al (2005). Oxytocin modulates neural circuitry for social cognition and fear in humans. J Neurosci 25: 11489-11493.

Kiss A, Mikkelsen JD (2005). Oxytocin - anatomy and functional assignments: a minireview. Endocr Regul 39: 97-105.

Kovacs GL, Vecsei L, Telegdy G (1978). Opposite action of oxytocin to vasopressin in passive avoidance behavior in rats. Physiol Behav 20: 801-802.

Lee H-J, Caldwell HK, Macbeth AH, Tolu SG, Young WS (2008). A conditional knockout mouse line of the oxytocin receptor. Endocrinology 149: 3256-3263.

Liberzon I, Sripada CS (2008). The functional neuroanatomy of PTSD: a critical review. Prog Brain Res 167: 151-169.

Lundeberg T, Uvnas-Moberg K, Agren G, Bruzelius G (1994). Antinociceptive effects of oxytocin in rats and mice. Neurosci Let 170: 153-157.

Macdonald K, Macdonald TM (2010). The peptide that binds: a systematic review of oxytocin and its prosocial effects in humans. Harv Rev Psychiatry 18: 1-21.

Marazziti D, Catena Dell'osso M (2008). The role of oxytocin in neuropsychiatric disorders. Curr Med Chem 15: 698-704.

McNish KA, Gewirtz JC, Davis M (1997). Evidence of contextual fear after lesions of the hippocampus: a disruption of freezing but not fear-potentiated startle. J Neurosci 17: 9353-9360.

Morgan CA, Grillon C, Southwick SM, Davis M, Charney DS (1995). Fear-potentiated startle in posttraumatic stress disorder. Biol Psychiatry 38: 378-385.

Nair HP, Gutman AR, Davis M, Young LJ (2005). Central oxytocin, vasopressin, and corticotropin-releasing factor receptor densities in the basal forebrain predict isolation potentiated startle in rats. J Neurosci 25: 11479-11488.

Neumann ID (2008). Brain oxytocin: a key regulator of emotional and social behaviours in both females and males. J Neuroendocrinol 20: 858-865.

Petrovic P, Kalisch R, Singer T, Dolan RJ (2008). Oxytocin attenuates affective evaluations of conditioned faces and amygdala activity. J Neurosci 28: 6607-6615.

Pitman RK, Orr SP, Lasko NB (1993). Effects of intranasal vasopressin and oxytocin on physiologic responding during personal combat imagery in Vietnam veterans with posttraumatic stress disorder. Psychiatry Res 48: 107-117.

Rescorla RA, Wagner AR (1972). A theory of Pavlovian conditioning: variations in the effectiveness of reinforcement and non-reinforcement. In: Black AH, Prokasy W (eds). Classical Conditioning II: Current Research and Theory. AppletonCentury-Crofts: New York. pp 64-99.

Richardson R (2000). Shock sensitization of startle: learned or unlearned fear? Behav Brain Res 110: 109-117.

Ring RH, Malberg JE, Potestio L, Ping J, Boikess S, Luo B et al (2006). Anxiolytic-like activity of oxytocin in male mice: behavioral and autonomic evidence, therapeutic implications. Psychopharmacology (Berl) 185: 218-225.

Ring RH, Schechter LE, Leonard SK, Dwyer JM, Platt BJ, Graf R et al (2010). Receptor and behavioral pharmacology of WAY-267464, a non-peptide oxytocin receptor agonist. Neuropharmacology 58: 69-77.

Risbrough VB, Brodkin JD, Geyer MA (2003). GABA-A and 5-HT1A receptor agonists block expression of fear-potentiated startle in mice. Neuropsychopharmacology 28: 654-663.

Risbrough VB, Geyer MA, Hauger RL, Coste S, Stenzel-Poore M, Wurst W et al (2009). CRF1 and CRF2 receptors are required for potentiated startle to contextual but not discrete cues. Neuropsychopharmacology 34: 1494-1503.

Rodrigues SM, Saslow LR, Garcia N, John OP, Keltner D (2009). Oxytocin receptor genetic variation relates to empathy and stress reactivity in humans. Proc Natl Acad Sci USA 106: 21437-21441. 
Rosen JB, Schulkin J (1998). From normal fear to pathological anxiety. Psychol Rev 105: 325-350.

Rotzinger S, Lovejoy DA, Tan LA (2010). Behavioral effects of neuropeptides in rodent models of depression and anxiety. Peptides 31: 736-756.

Rougemont-Bücking A, Linnman C, Zeffiro TA, Zeidan MA, Lebron-Milad K, Rodriguez-Romaguera J et al (2010). Altered processing of contextual information during fear extinction in PTSD: an fMRI Study. CNS Neurosci Ther, print copy in press (originally published online 16 April 2010, at http://www3. interscience.wiley.com/journal/119423678/).

Savaskan E, Ehrhardt R, Schulz A, Walter M, Schächinger H (2008). Post-learning intranasal oxytocin modulates human memory for facial identity. Psychoneuroendocrinology 33: 368-374.

Swerdlow NR, Weber M, Qu Y, Light GA, Braff DL (2008). Realistic expectations of prepulse inhibition in translational models for schizophrenia research. Psychopharmacology (Berl) 199: 331-388.

Uvnäs-Moberg K, Ahlenius S, Hillegaart V, Alster P (1994). High doses of oxytocin cause sedation and low doses cause an anxiolytic-like effect in male rats. Pharmacol Biochem Behav 49: 101-106.

Uvnäs-Moberg K, Björkstrand E, Salmi P, Johansson C, Astrand M, Ahlenius S (1999). Endocrine and behavioral traits in lowavoidance Sprague-Dawley rats. Regul Pept 80: 75-82.

Uvnäs-Moberg K, Eklund M, Hillegaart V, Ahlenius S (2000). Improved conditioned avoidance learning by oxytocin admin- istration in high-emotional male Sprague-Dawley rats. Regul Pept 88: 27-32.

Vaidyanathan U, Patrick CJ, Cuthbert BN (2009). Linking dimensional models of internalizing psychopathology to neurobiological systems: affect-modulated startle as an indicator of fear and distress disorders and affiliated traits. Psychol Bull 135: 909-942.

Veening JG, de Jong T, Barendregt HP (2010). Oxytocin-messages via the cerebrospinal fluid: Behavioral effects; a review. Physiol Behav print copy in press (originally published online 20 May 2010, at http://www.sciencedirect.com/science/journal/00319384).

Walker DL, Davis M (2002a). Quantifying fear potentiated startle using absolute vs proportional increase scoring methods: implications for the neurocircuitry of fear and anxiety. Psychopharmacology (Berl) 164: 318-328.

Walker DL, Davis M (2002b). The role of amygdala glutamate receptors in fear learning, fear-potentiated startle, and extinction. Pharmacol Biochem Behav 71: 379-392.

Winslow JT, Hearn EF, Ferguson J, Young LJ, Matzuk MM, Insel TR (2000). Infant vocalization, adult aggression, and fear behavior of an oxytocin null mutant mouse. Horm Behav 37: 145-155.

Winslow JT, Noble PL, Davis M (2007). Modulation of fearpotentiated startle and vocalizations in juvenile rhesus monkeys by morphine, diazepam, and buspirone. Biol Psychiatry 61: 389-395. 